\title{
Magnetic Measurement of the Thickness of Composite Copper and Nickel Coatings on Steel
}

\author{
By Äbner Brenner and Eugenia Kellogg
}

\begin{abstract}
A magnetic method has been developed for measuring the thickness of composite coatings of copper and nickel, electrodeposited on steel. The method consists in measuring the attractive force between the specimen and two permanent magnets of different strengths. The total thickness of the deposit and the relative thickness of copper and nickel layers can be determined from a set of calibration curves.
\end{abstract}

In the plating industry composite coatings of copper and nickel are extensively used, although they do not generally yield as good a protective value as an equal thickness of pure nickel. These composite coatings on steel consist of two layersthe first, copper, which is electrodeposited directly on the steel, and the second, nickel, deposited on the copper. The copper is less expensive than nickel, and it may be readily buffed as an undercoat for bright nickel. The present trend is toward the use of heavier composite coatings to secure increased protective value. The automotive industry commonly uses copper-nickel deposits up to 0.002 in. thick on steel parts. It is therefore desirable to obtain a nondestructive method of measuring the total thickness and the relative thicknesses of the copper and nickel layers such as described in this paper.

An instrument known as the Magne-gage has been used to measure the thickness of nonmagnetic and of nickel coatings on steel. ${ }^{1}$ This instrument measures the attractive force between a small permanent magnet and the plated sample. This attractive force is dependent upon the thickness of the coating and the magnetic properties of the coating and base material. When a coating is interposed between the magnet and the magnetic base material, the attractive force is decreased, provided that the coating is less magnetic than the base material, the decrease being greater the thicker the coating.

\footnotetext{
1 Abner Brenner, J. Research NBS 20, 357 (1938) RP1081.
}

The Magne-gage is a spring balance, on one arm of which the magnet is suspended. A helical spring is attached in such a manner that as the knob is turned, the spring is wound up. The force required to detach the magnet is a measure of the attraction between the magnet and the specimen. The attractive force of the magnet for the sample is read from a dial attached to the turning knob. The thickness of the coating is determined from this reading with the aid of a calibration curve made with coatings of known values of thickness. To determine the thickness of composite coatings, two magnets of different strengths are used. In order to compensate for the difference in the attractive force of the two magnets, it would be necessary to use two different gages unless different springs were used or two magnets were hung at different distances from the pivot on the balance arm. For the measurements here reported, the stronger magnet was hung nearer to the pivot. The modified gage is shown in figure 1.

Nickel is somewhat magnetic, although not as much so as steel, hence the calibration curve for the nickel coatings differs from that for copper coatings as copper is practically nonmagnetic. As can be seen from figure 2 , the calibration curve for pure nickel coatings of given values of thickness falls considerably to the left of the curve for pure copper, and is steeper. The calibration curve for any composite coating must fall within the boundaries of these two curves as, for ex- 


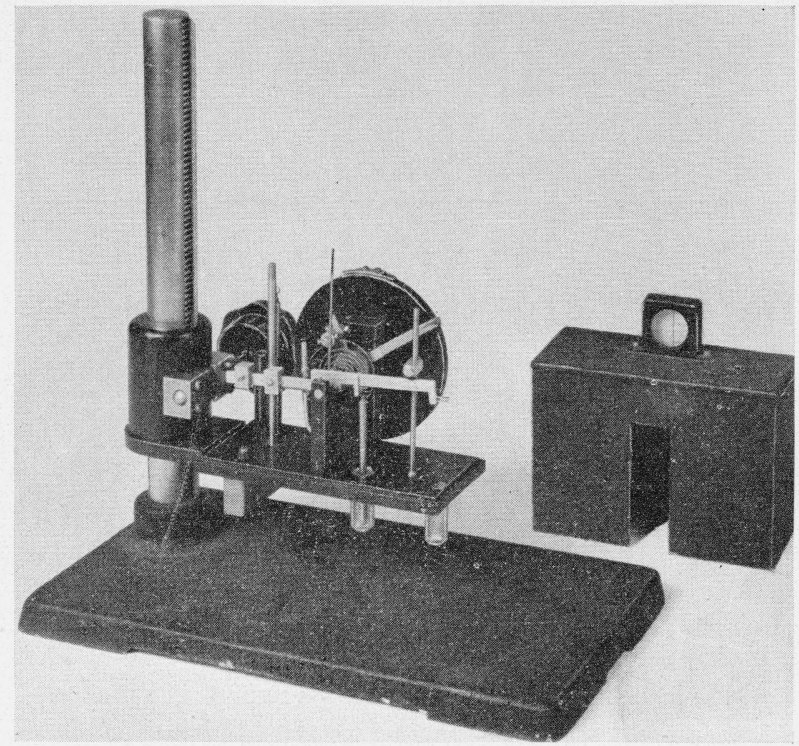

FIGURE 1. Magne-gage for measuring thickness of composite coatings.

ample, does the curve for equal thickness of copper and nickel. In the absence of knowledge of the relative thickness of copper and nickel, the total thickness cannot be determined from a single reading as a certain reading can represent a number of thicknesses. For instance, in figure 2 , a dial reading of 70 would represent a total thickness of 0.00049 in. of pure copper; 0.00085 in. of a half copper and half nickel coating; or $0.00168 \mathrm{in}$. of a pure nickel coating.

It is possible, by making measurements on a

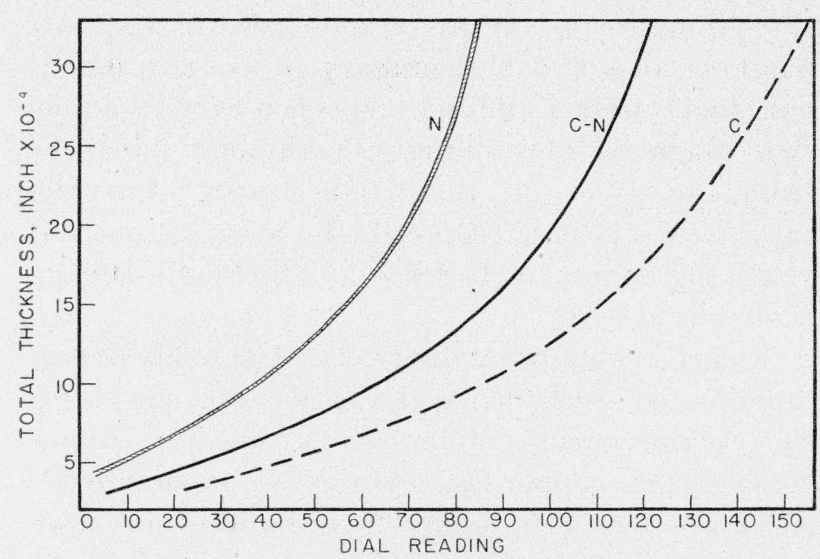

Figure 2. Calibration curves for coatings of various percentages of copper and nickel on steel.

$N$, 100-percent-nickel coating; $C-N$, 50-percent-copper-50-percent-nickel coating; $C, 100$-percent-copper coating. coating with two magnets of different strengths, to determine not only the total thickness but also the relative thickness of the two layers. This method is based on the fact that the calibration curves of magnets of different strengths have quite different curvatures. This is illustrated in figure 3 , where the stronger magnet has about three times the magnetic strength of the weaker magnet. Curves for composite coatings of different compositions, such as 100-percent copper, half copper-half nickel, and 100-percent nickel were prepared, as shown in figures 4 and 5 . Suppose that on a given sample a dial reading of 78 was obtained with the weaker magnet, and a reading of 80 was obtained with the stronger

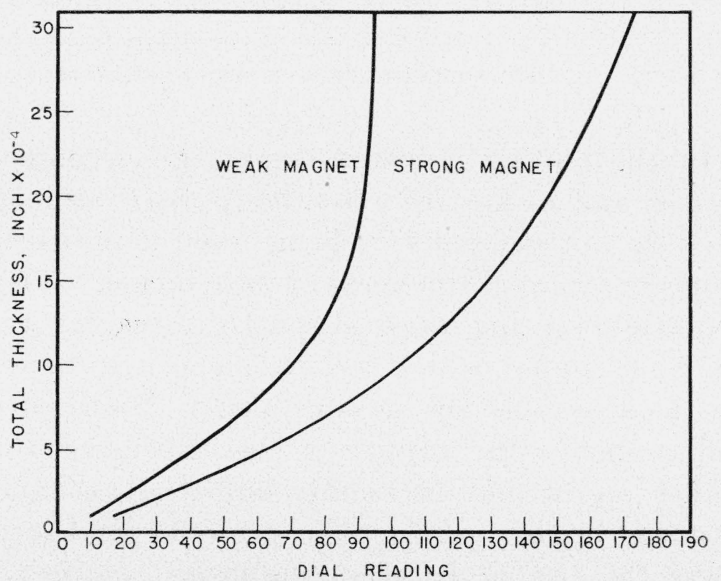

Figure 3. Calibration curves for two magnets of different strengths with copper coatings on steel.

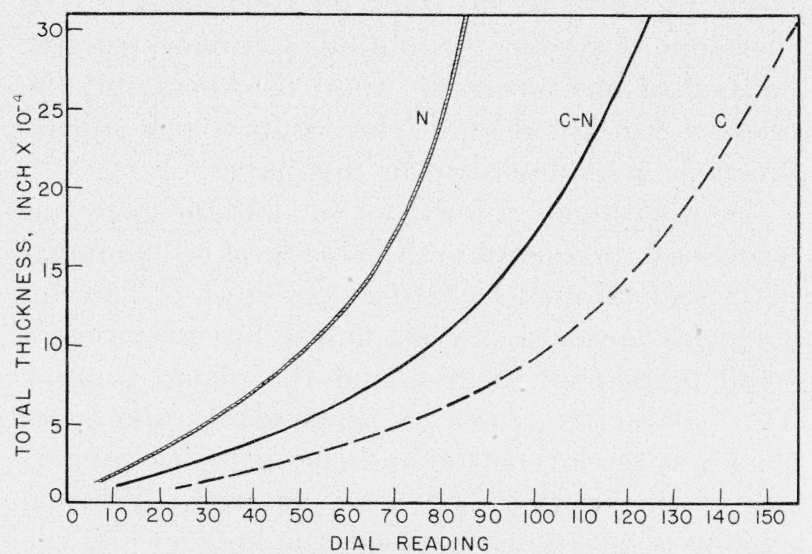

Figure 4. Calibration curves of coatings containing various percentages of copper and nickel on steel for the strong magnet.

$N$, 100-percent-nickel coating; $C-N, 50$-percent-copper-50-percent-nickel coating; $C, 100$-percent-copper coating. 


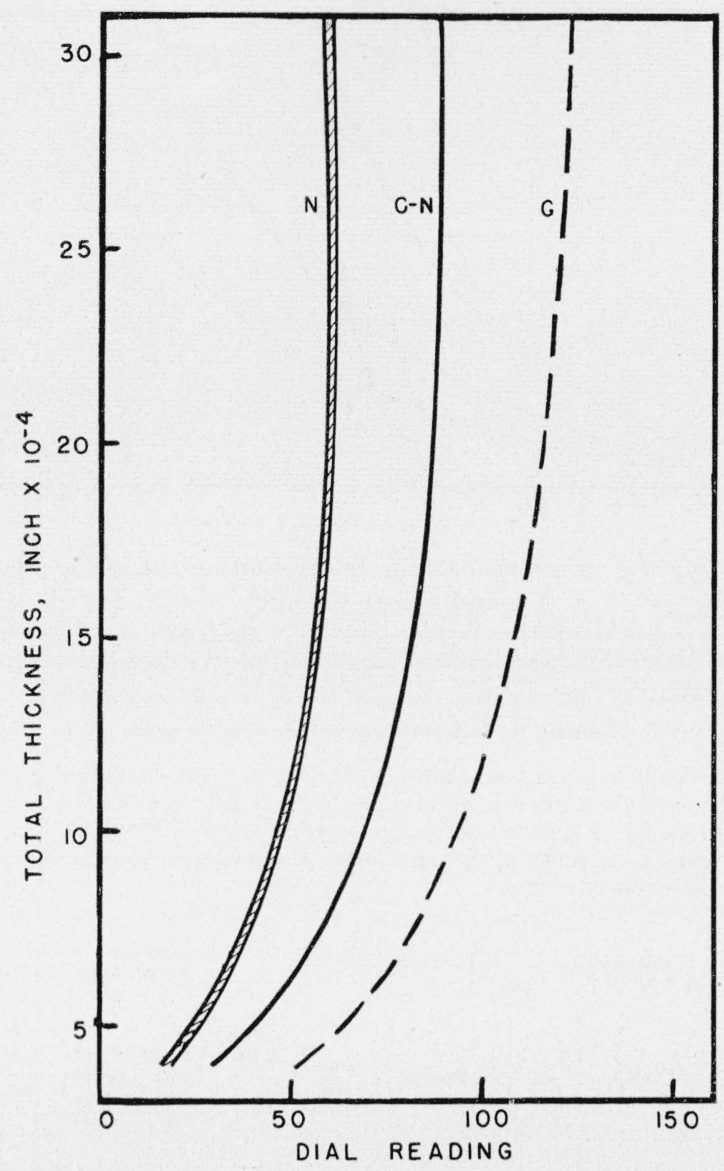

Figure 5. Calibration curves of coatings containing various percentages of copper and nickel on steel for the weak magnet.

$N$, 100-percent-nickel coating; $C-N$, 50-percent-copper-50-percent-nickel coating; $C, 100$-percent-copper coating.

magnet. Assuming that the sample has percentages of copper and nickel represented by one of the calibration curves, there are six possibilities as to the thickness as follows:

\begin{tabular}{|c|c|c|}
\hline & \multicolumn{2}{|c|}{$\begin{array}{l}\text { Thickness, } \\
\text { inch } \times 10^{-4}\end{array}$} \\
\hline & Magnet 1 & Magnet 2 \\
\hline If $100 \%$ copper. & 7. 2 & 9. 0 \\
\hline If $50 \%$ copper-50\% nickel__.... & 13. 4 & 13. 4 \\
\hline If $100 \%$ nickel $\ldots$ & $>30.0$ & 26. 2 \\
\hline
\end{tabular}

The thickness must be the same when measured by each magnet and in this case is 0.00134 in. The percentage of copper or nickel is defined by the point where the thickness readings for the two magnets coincide. Therefore in the above case half the total thickness must be copper. If the relative percentage of copper does not correspond to a specified curve, it becomes necessary to interpolate between the curves.

To avoid cumbersome, lengthy tabulations, the following graphical method has been developed. The method involves the superposition of the graphs for one magnet on those for the other so that the pertinent gage readings coincide. The points of intersection of the curves are noted. In figure 6, the reading of 78 with the weaker magnet is superposed on the reading of 80 with the stronger magnet, at the line $A B$. Although the curves intersect at a number of points, those of like composition cross at only three points, $X, Y$, and $Z$. Through those points line $X Z$ is drawn. The intersection $Q$ of the line $A B$ and the line $X Z$ defines the total thickness, in this case 0.00134 in., measured on the left scale. As the thickness falls on the calibration curve for half copper and half nickel, it is not necessary to interpolate to determine the percentage of copper or nickel. If the interpolation is necessary, it may be done in the following manner. Suppose that a reading

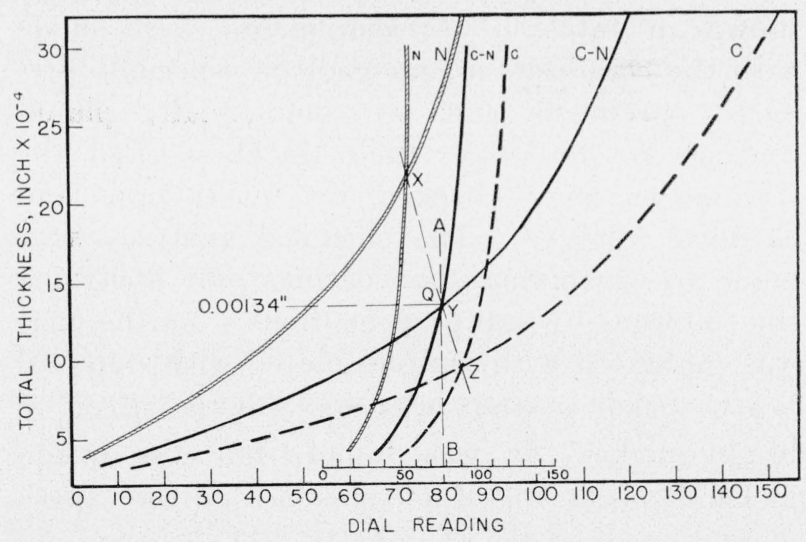

FiguRE 6. Superposition of calibration curves of the weak (fig. 5) and strong (fig. 4) magnets.

Intersection occurs on the half-copper-half-nickel curve. $N, 100$-percentnickel coating; $C-N$, 50-percent-copper-50-percent-nickel coating; $C, 100$ percent-copper coating. 
of 68 is obtained with the weak magnet and a reading of 75 with the strong, and the curves are superposed as above. In figure 7 , the two dial readings are represented by line $A B$. A line $X Z$ is drawn through the points $X, Y$, and $Z$ where curves of like percentages of copper intersect. The position of point $Q$, where $A B$ cuts $X Z$, defines the thickness (0.00172 in.), which is read off from the ordinate, and also the percentage of the total thickness that is copper. Point $Q$ lies somewhere between points $X$ and $Y$, i. e., between the calibration curves for pure nickel and half copper and half nickel, hence the percentage of copper must fall between these two. As $Q$ lies along line $X Z$ about 40 percent of the distance from the half copper curve to the nickel curve, the copper content is $(40 / 100) \times 50=20$-percent copper. Although the variation in composition is not linear along line $X Z$, we may assume it to be linear, without appreciably increasing the error in the determination of the percentage of copper of the coating.

The gage as designed will measure with a satisfactory accuracy composite coatings with total thicknesses from 0.0005 to 0.0030 in. Below and above this range the superimposed curves for the two magnets run virtually parallel. Within this range the error of the gage was found to be about 10 percent for the total thickness and 15 percent for the copper percentage determination, as shown in table 1. Measurements were made with the composite magne-gage on especially prepared specimens and on commercially plated coatings to determine their thickness; and the thicknesses were checked by microscopic and chemical analysis. The chemical analyses were made by dissolving the coatings and analyzing the solutions by standard methods. As the gage was calibrated with samples plated with standard Watts nickel, a study was made of the effects of bright nickel. It was found that the bright nickel deposits caused no error beyond the experimental errors of the gage itself. The accuracy of the gage may be seen in figure 8 and table 1, which include bright nickel coatings as well as Watts nickel.

The sample must meet certain requirements to yield satisfactory measurements. An area at least 1-in. square is required, especially for the stronger magnet. If this area is unobtainable, the sample

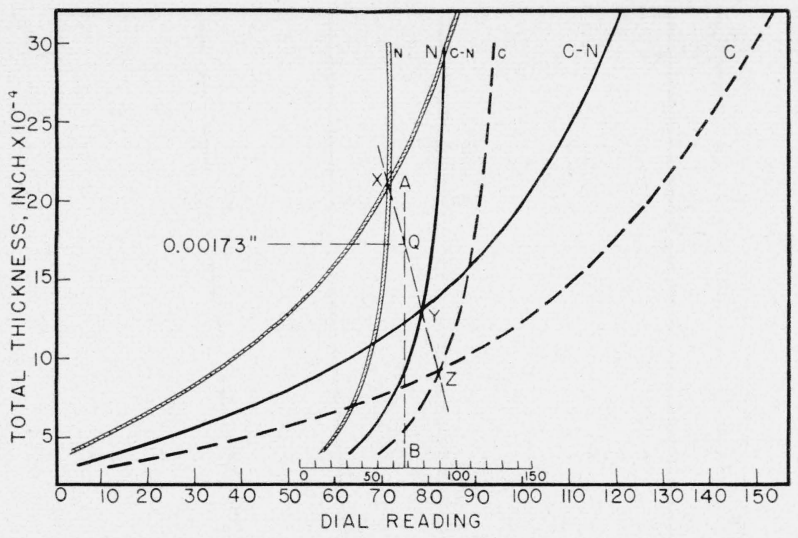

Figure 7. Superposition of calibration curves of the weak and strong magnets.

Intersection interpolated between curves. $N$, 100-percent-nickel coating; $C-N$, 50-percent-copper-50-percent-nickel coating; $C$, 100-percent-copper coating.

\section{TABLE 1. Accuracy of composite gage}

The percentage deviation is based on the total thickness obtained by chemical analysis. In most cases microscopic thickness measurements were made on areas adjacent to those used for the chemical analyses. Where the sample was found to be uniform, the microscopic determinations were concordant with the chemical results.

\begin{tabular}{|c|c|c|c|c|c|c|c|c|}
\hline \multicolumn{3}{|c|}{ Specimen } & \multicolumn{2}{|c|}{ Total thickness } & \multirow[b]{2}{*}{$\begin{array}{c}\text { Devia- } \\
\text { tion }\end{array}$} & \multicolumn{3}{|c|}{$\begin{array}{l}\text { Thickness of copper, } \\
\text { percentage of total }\end{array}$} \\
\hline No. & $\begin{array}{c}\text { Plating } \\
\text { by }{ }^{\mathrm{a}}\end{array}$ & $\begin{array}{l}\text { Type } \\
\text { of } \\
\text { nick- } \\
\text { el b }\end{array}$ & $\begin{array}{l}\text { Chemical } \\
\text { analysis }\end{array}$ & $\begin{array}{l}\text { Compos- } \\
\text { ite gage } \\
\text { results }\end{array}$ & & $\begin{array}{c}\text { Chem- } \\
\text { ical } \\
\text { anal- } \\
\text { ysis }\end{array}$ & $\begin{array}{l}\text { Com- } \\
\text { posite } \\
\text { gage } \\
\text { results }\end{array}$ & $\begin{array}{l}\text { Differ- } \\
\text { ence } \\
\text { in per- } \\
\text { cent- } \\
\text { age of } \\
\text { copper }\end{array}$ \\
\hline 1 & Com & B & $\begin{array}{c}\text { Inch } \\
40 \times 10^{-5}\end{array}$ & $\begin{array}{c}\text { Inch } \\
31 \times 10^{-5}\end{array}$ & $\begin{array}{l}\text { Per- } \\
\text { cent } \\
-23\end{array}$ & 63 & 100 & 37 \\
\hline 2 & $\ldots$ do $\ldots$ & $\mathrm{B}$ & 61 & 52 & -15 & 44 & 50 & 6 \\
\hline 3 & $\ldots$ do $\ldots . . .$. & B & 63 & 62 & -2 & 21 & 30 & 9 \\
\hline 4 & do & $\mathrm{B}$ & 66 & 109 & +65 & 84 & 76 & -8 \\
\hline 5 & NBS & $\mathrm{B}$ & 71 & 73 & 3 & 0 & 10 & +10 \\
\hline 6 & _._. do_... & B & 76 & 72 & -6 & 35 & 45 & 10 \\
\hline 7 & Com ..... & B & 77 & 72 & -7 & 38 & 54 & 16 \\
\hline 8 & NBS $\ldots$ & $\mathrm{B}$ & 78 & 76 & -3 & 35 & 40 & 5 \\
\hline 9 & Com ..... & B & 87 & 86 & -1 & 86 & 76 & -10 \\
\hline 10 & $\ldots$ do & B & 86 & 87 & +1 & 38 & 30 & -8 \\
\hline 11 & ...do_.. & $\mathrm{B}$ & 93 & 82 & -12 & 24 & 30 & +6 \\
\hline 12 & $\ldots$ do $\ldots . . . . .$. & W & 97 & 93 & -4 & 57 & 60 & 3 \\
\hline 13 & . do & W & 102 & 86 & -16 & 56 & 70 & 14 \\
\hline 14 & NBS & W & 105 & 100 & -4 & 76 & 75 & -1 \\
\hline 15 & ... do & B & 113 & 132 & +17 & 24 & 25 & +1 \\
\hline 16 & Com.. & B & 130 & 128 & -2 & 20 & 8 & -12 \\
\hline 17 & $\ldots$ do & W & 136 & 134 & -1 & 59 & 55 & -4 \\
\hline 18 & NBS & W & 148 & 152 & +3 & 75 & 80 & +5 \\
\hline 19 & _. do & W & 149 & 166 & 11 & 75 & 60 & -15 \\
\hline 20 & Com & W & 150 & 145 & -3 & 59 & 55 & -4 \\
\hline 21 & NBS.. & W & 191 & 185 & -3 & 25 & 25 & 0 \\
\hline 22 & . do & W & 199 & 205 & +3 & 75 & 80 & +5 \\
\hline 23 & _. do & W & 201 & 235 & 17 & 25 & 33 & 6 \\
\hline 24 & . do & W & 247 & 222 & -10 & 25 & 40 & 15 \\
\hline
\end{tabular}

a Com refers to commercially plated samples; NBS to those plated at the National Bureau of Standards.

b $\mathrm{B}$ refers to bright nickel; W to Watts nickel. 


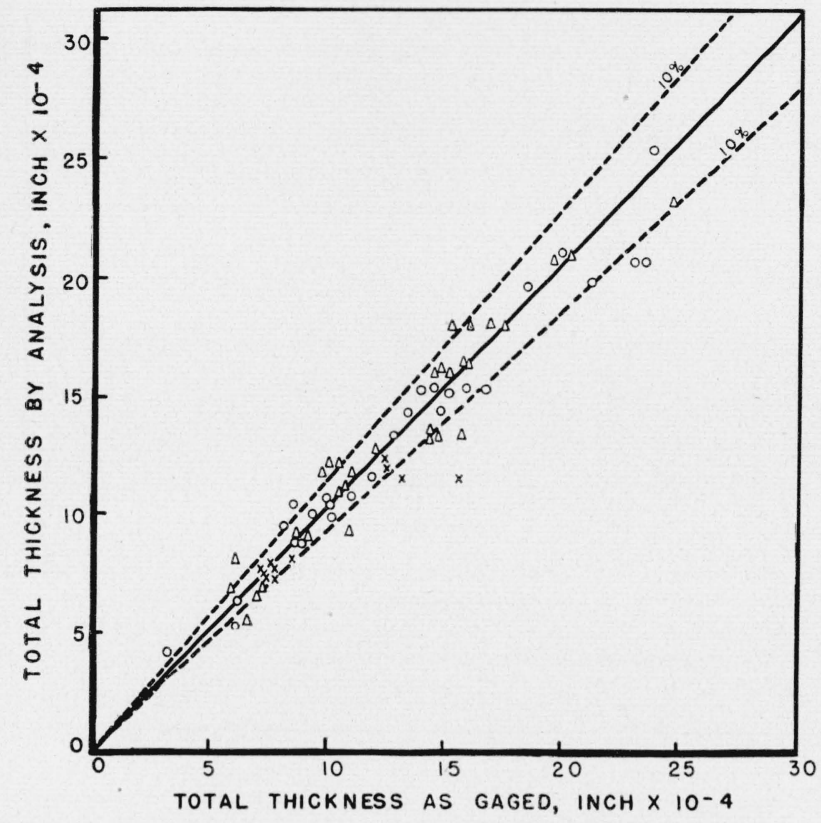

Figure 8. Accuracy of the composite coating Magne-gage.

The dotted lices represent a 10-percent deviation of thickness obtained by gaging from the thickness obtained by analysis. Watts nickel, $\bigcirc$, chemical analysis; $\triangle$, metallurgical analysis; bright nickel, $X$, chemical analysis. should be placed on a larger steel backing. The specimen should have a radius of curvature of not less than half an inch. An error of one dial division will cause an appreciable error in thickness. For example, with the weaker magnet in the range from 0.001 in. to 0.0020 in., one dial division will cause an error of 0.00014 in., or about 8 percent, if the sample is pure nickel; and with the stronger magnet an error of 0.00006 in., or about 5 percent. Care therefore must be taken in making the readings, and in providing an adequate area and a sufficient radius of curvature.

For the initial calibration and subsequent checking of this gage, standard-thickness samples will be provided. For each composition of coating, each set will consist of four specimens with different thicknesses of coating on steel. It is probable that all requirements can be met by three sets of specimens, consisting respectively of (a) pure nickel, (b) half copper and half nickel, and (c) pure copper.

Washington, October 20, 1947. 